\title{
Article
}

\section{Wheelchair Skills Education and Training for Children with Spina Bifida and/or Hydrocephalus and Their Parents: A Pilot Study}

\author{
Rosemary Joan Gowran ${ }^{1,2,3, *(\mathbb{D})}$, Marion B. Collins ${ }^{4}$, Joanne McGlanaghy ${ }^{4}\left(\mathbb{D}\right.$, Ellen Shanahan ${ }^{4}$ and \\ Yvonne Cleary ${ }^{5}$
}

check for updates

Citation: Gowran, R.J.; Collins, M.B.; McGlanaghy, J.; Shanahan, E.; Cleary, Y. Wheelchair Skills Education and Training for Children with Spina Bifida and/or Hydrocephalus and Their Parents: A Pilot Study. Disabilities 2022, 2, 96-118. https://doi.org/10.3390/ disabilities2010009

Academic Editor: John Krakauer

Received: 23 November 2021

Accepted: 28 January 2022

Published: 22 February 2022

Publisher's Note: MDPI stays neutral with regard to jurisdictional claims in published maps and institutional affiliations.

Copyright: (C) 2022 by the authors. Licensee MDPI, Basel, Switzerland. This article is an open access article distributed under the terms and conditions of the Creative Commons Attribution (CC BY) license (https:// creativecommons.org/licenses/by/ $4.0 /)$.
1 Discipline Occupational Therapy, School of Allied Health, Faculty of Education and Health Sciences, Health Research Institute, Health Implementation Science and Technology, University of Limerick, V94 T9PX Limerick, Ireland

2 School of Health and Sports Science, University of the Sunshine Coast, Maroochydore, QLD 4558, Australia

3 Assisting Living and Learning (ALL) Institute, Maynooth University, W23 VP22 Maynooth, Ireland

4 Discipline Occupational Therapy, School of Allied Health, Faculty of Education and Health Sciences, University of Limerick, V94 T9PX Limerick, Ireland; marion.b.collins@gmail.com (M.B.C.); jomcglan@icloud.com (J.M.); elleshan1995@gmail.com (E.S.)

5 School of English, Irish, and Communication, Technical Communication and Instructional Design, University of Limerick, V94 T9PX Limerick, Ireland; yvonne.cleary@ul.ie

* Correspondence: rosie.gowran@ul.ie

\begin{abstract}
Background: Many children with spina bifida and/or hydrocephalus use manual wheelchairs. However, training to ensure appropriate wheelchair use is limited and informal, and this negatively impacts daily activity and participation. Evidence suggests formal training can increase children's confidence and independence, with early intervention being critical for healthy development. In Ireland, like in many other regions internationally, such interventions are not readily available to families. Aim and objectives: The overall aim of the study was to pilot wheelchair skills training for children aged 3-8 years with spina bifida and/or hydrocephalus and their parents, to develop a sustainable program. The objectives were: (1) to develop and evaluate a wheelchair skills information pack; (2) to investigate the impact of training on children's performance of wheelchair skills; (3) to explore parents' perspectives on how training influenced their children's daily participation; (4) to identify beneficial aspects of program delivery for children and parents. Methods: We applied a mixed-methods study design that included three stages: (1) evaluation of the use of a bespoke wheelchair skills information pack; (2) within-subject pre-post analysis of the wheelchair skills test (WST) and individual training goals; (3) qualitative thematic analysis of Photovoice documentary narratives from focus groups with parents. Results: Four children and their parents participated in the study. Parents reported the wheelchair skills information pack to be useful, recommending more child-friendly images, and the provision of the pack when children first receive their wheelchairs. Analysis of the pre/post-WST showed an increase in the performance of skills. Parents' perspectives and experiences are captured in two Photovoice themes: (1) children developing their skills, (2) supporting parents to support their children. Conclusion: The pilot program was a success for these families, highlighting potential gaps in Irish wheelchair provision services and the need for wheelchair skills education and training to support parents and children.
\end{abstract}

Keywords: wheelchair skills training program; wheelchair skills test (WST); wheelchair skills information pack; photovoice; spina bifida and/or hydrocephalus (SB and/or $\mathrm{H}$ )

\section{Introduction}

The provision of a wheelchair can improve the quality of life of individuals with impaired mobility. The use of a wheelchair facilitates engagement in activities of daily living, and is thus central to an individual's identity, life experience and human rights [1-3]. 
There appears to be a noticeable gap in services for the promotion of self-management and manual wheelchair skills training programs for children with spina bifida (SB) and/or hydrocephalus $(\mathrm{H})$ in Ireland, the location of this study. Skills gaps also exist in other regions of the globe [1-3].

Spina bifida is recorded in all regions of the globe [4] and is reported to affect $1 / 1000$ children born per year in Ireland, one of the highest incidences in the world [5]. The term spina bifida (SB) defines a group of birth defects caused by the incomplete closure of the spinal column [5]. Hydrocephalus is present in $90 \%$ of those born with the condition [6]. Hydrocephalus $(\mathrm{H})$, a condition caused by disordered homeostasis of the cerebrospinal fluid, is a term used to describe the enlargement of the ventricles of the brain [7]. Gross motor skills are impacted due to $\mathrm{SB}$ and/or $\mathrm{H}$, such as mobility and spatial navigation $[8,9]$. Motor symptoms associated with SB include paralysis from the level of, or from just below, the lesion; low or abnormal muscle tone; poor postural control; and poor coordination [10,11]. Secondary to these symptoms, $51 \%$ of children diagnosed with SB/H are prescribed a mobility aid, such as a wheelchair, walker, or braces, for independent mobilization [12].

Challenges facing children with SB and/or $\mathrm{H}$ and their parents in Ireland include gaining access to appropriate wheelchair provision, wheelchair skills training and educational resources [13]. Such challenges contribute to several issues raised in research, such as mobility and participation barriers commonly experienced by wheelchair users [14]. A lack of training can cause a higher prevalence of wheelchair accidents [15]. Children are at a higher risk of wheelchair-related injuries due to their age-appropriate exploratory behavior and are likely to be injured in unfamiliar environments [16,17]. Accidents and reduced mobility can negatively affect motivation, self-efficacy and confidence, and may lead to learned helplessness, where children become dependent on family, resulting in a reduced ability to self-manage [18-23].

Wheelchair skills training can address these challenges while positively influencing wheelchair users' levels of independence and participation in meaningful occupations [14,24-26]. Indeed, the 2006 United Nations Convention on the Rights of Persons with Disabilities, Article 20, asserts the need for nations to provide training in the use of mobility devices [27]. The 2008 World Health Organization's (WHO) Wheelchair Provision Model outlines best practice guidelines and a care pathway, which include training about wheelchair skills $[28,29]$. Early intervention for self-directed mobility is not only critical to support safe wheelchair use, but also for neurological development, by increasing opportunities to engage in physical activity and play. Early intervention promotes long-term intrinsic motivation for social engagement, physical health and wellbeing, decreasing the risk of developing secondary complications, including include type 2 diabetes, obesity and coronary heart disease $[24,30,31]$. The environmental context also plays a critical role in the level of participation experienced by children; contextual factors include children's support network and their parents.

Parents of young children often feel uncertainty and require resources to support their children's changing needs [32]. Despite the emphasis in research on family centeredness in services for children [33,34], studies have found a lack of reasoned consideration given to supports that meet different family needs $[32,35]$. Currently, limited research exists that investigates the effectiveness of, and best practice in developing, manual wheelchair skills training and education for children, with no current standardized protocol [36-39]. Similarly, minimal research has focused on examining parents' insights and perspectives to inform the development of resources in this area that better support family needs.

Therefore, the aim of this research is to pilot wheelchair skills training for children aged 3-8 years with spina bifida and/or hydrocephalus (SB and/or $\mathrm{H}$ ) and their parents, to develop a sustainable program. The specific objectives are:

(1) To develop and evaluate a wheelchair skills information pack.

(2) To investigate the impact of training on children's performance of wheelchair skills.

(3) To explore parents' perspectives on how training has influenced children's daily participation. 
(4) To identify beneficial aspects of program delivery for children and parents.

\section{Materials and Methods}

The national association Spina Bifida Hydrocephalus Ireland (SBHI) and the University of Limerick came together to determine the benefits of a pilot wheelchair skills training program (WSTP) for children aged 3-8 years. The contribution of this research is to support SBHI to plan and implement a sustainable nationwide wheelchair skills training program for children.

\subsection{Study Design}

This pilot study involved mixed methods, combining quantitative (questionnaires and checklists) and qualitative (open-ended written comments, Photovoice and focus groups) approaches to facilitate the understanding of a multifaceted phenomenon [40,41]. A participatory action research (PAR) framework using Photovoice was applied in the study design [42-44]. In PAR projects, participants share in the coproduction of learning, knowledge and action-oriented results, which aims to influence change within a community and improve individuals' lives [42-45]. PAR sought to empower parents in the study to share their experiences of participation in the WSTP. PAR is also recognized as being complementary to other research paradigms that include children [44]. In this study, researchers collaborated with parents, children living with SB and/or $\mathrm{H}$ and SBHI representatives (including the research and training coordinator, a physiotherapist who is a qualified wheelchair skills trainer and a wheelchair user who supported the skills training) to investigate the research topic.

\subsection{Participants}

Participants were recruited through SBHI, the gatekeeper organization; a poster information leaflet outlining the details of the pilot program was sent to registered members of the association via email. Inclusion criteria were: children aged $3-8$ years, who required a manual wheelchair as a mobility aid and had a diagnosis of SB and/or $\mathrm{H}$ and their parent/s. Participants needed to speak fluent English, and a minimum of one parent/guardian needed to be present during all sessions. Children were ineligible without the participation of at least one parent.

\subsection{Study Procedure, Timeline and Data Collection}

The study design incorporated a pre-training program, pre- and post-training measures and program evaluation.

\subsubsection{Pre-Training Program}

A wheelchair skills information pack [46] was designed prior to the start of the program. The design of the resource was informed by the following steps and strategies.

\section{Wheelchair Skills Training Information Pack Content}

Informed by a literature review, an information pack was developed, incorporating best practice guidelines to encourage children to practice their wheelchair skills and advise on the grading of skills to match the child's current level of ability. Within the pack, each skill descriptor included the skill name, a description of the skill, the rationale for each skill and guidance points on how to complete the skill. This format was informed by Kirby's work [47] in this field. SBHI representatives and university faculty members evaluated and provided feedback on drafts to inform the design of the final information pack. The first four pages of the pack are illustrated in Figure 1. 


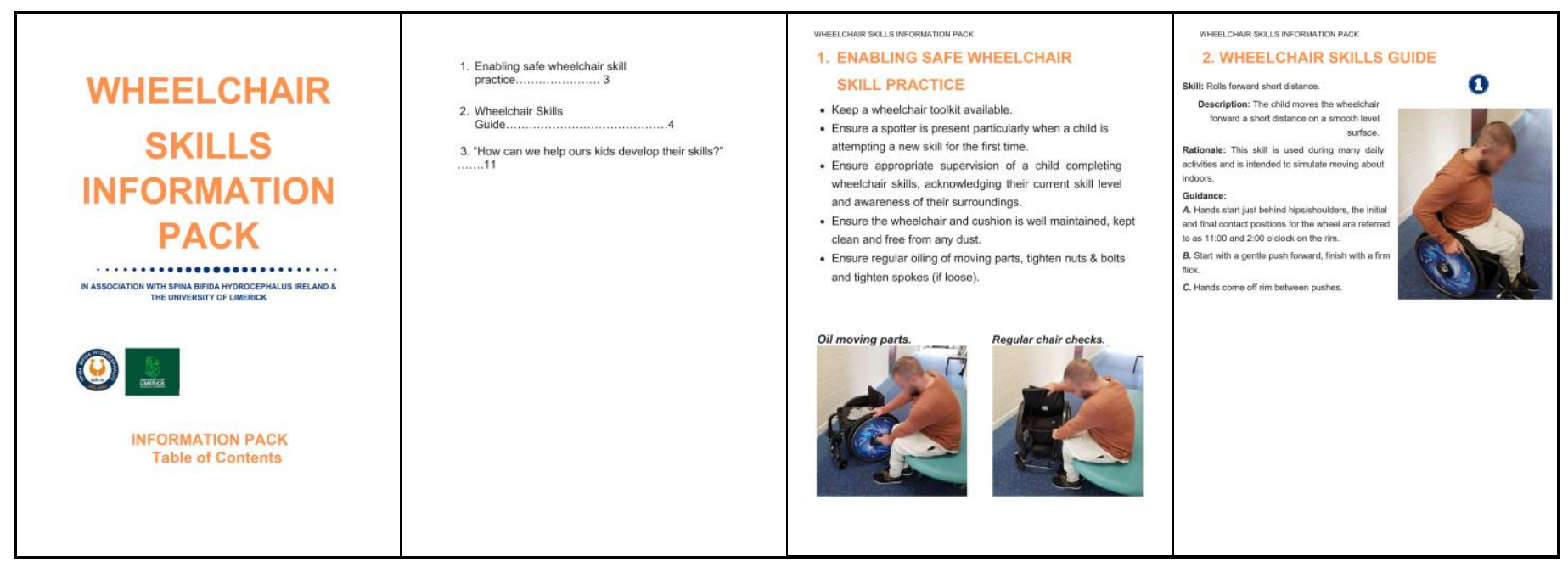

Figure 1. Images of the first four pages of the wheelchair skills information pack.

Images and Graphic Design for Accessibility

The design is minimalist, to encourage a strong focus on the educational content. Images and content from a wheelchair service training package by the World Health Organization (WHO) were initially explored [48].

Plain language and images were used to enhance usability for children and their families. Previously completed studies of a similar nature recommend the inclusion of more context-relevant visuals instead of text-heavy content. This promotes the easier transfer of knowledge to the target audience $[49,50]$.

\subsubsection{Introducing the Training Program and the Photovoice Method}

The training program was introduced in a focus group with parents. Focus groups offer a medium for the analysis of different perspectives, allowing participants to introduce and clarify ideas during group discourse [51-54]. Table 1 outlines the training program schedule, and the activities and data gathered during the program.

During the introductory focus group, parents were also introduced to Photovoice, a PAR method [43] used to empower participants to highlight their mobility concerns, to evaluate the program and to share experiences. Photovoice involves photo narrative descriptions, representing individuals' lived experiences through self-identified images and language [44,55]. Table 2 shows the question guide used to explore the experiences [56] of wheelchair skills training during Focus Groups 1 and 2.

Parents were asked to contribute as co-researchers documenting, with photographs and narrative descriptions, their children practicing, developing and implementing the skills they were learning. They were asked to select five pictures by the final week with titles and narrative descriptions explaining what was important or meaningful about each image. Parents received a Photovoice guide, adapted with reference to the literature $[43,44,55]$, which included a list of prompts to help parents develop a plan for taking pictures. They were asked to take pictures using their individual smartphones, a viable option as picture quality is high, and participants are familiar with settings and functionality.

\subsubsection{Pre- and Post-Training Measures}

\section{Demographic Questionnaire}

On the first day of the training program, parents completed a demographic questionnaire; this instrument gathered background information about participants e.g., sex and age, as well as about the type of wheelchair use for each participant. These data provided context on the heterogeneity of the participants and facilitated data analysis. 
Wheelchair Skills Information Pack and Open-Ended Questionnaire

Parents received their copy of the wheelchair skills information pack and an openended questionnaire (Supplementary File S1). The questionnaire was developed using a PAR approach to interpret and record participants' viewpoints on the resource $[42,51]$ and inform recommendations for its future development. Parents were required to rate the information pack, in terms of assisting children with their wheelchair skills and its potential use at home, through two 5-point Likert Scale questions. The seven open-ended questions covered various aspects of usability, usefulness and potential improvements to functionality and presentation. Parents were asked to return their completed questionnaires on the final day of the program.

Table 1. Wheelchair skills training program schedule.

\begin{tabular}{|c|c|}
\hline Training Program & Activities \\
\hline $\begin{array}{c}\text { Day } 1 \\
\text { Baseline information }\end{array}$ & $\begin{array}{ll}\text { - } & \text { Demographic questionnaire } \\
\text { - } & \text { Wheelchair Skills Test (WST) and } \\
\text { observation } \\
\text { - } \quad \text { Goal setting }\end{array}$ \\
\hline $\begin{array}{c}\text { Day } 2 \\
\text { Skills training }\end{array}$ & $\begin{array}{ll}\text { Skills } & \text { Taught } \\
- & \text { Forward/backward propulsion } \\
- & \text { Stopping } \\
- & \text { Turns in place } \\
- & \text { Turns while moving } \\
- & \text { Maneuver sideways } \\
- & \text { Picks up object } \\
- & \text { Energy conservation (with family) } \\
- & \text { Shoulder preservation (with family) }\end{array}$ \\
\hline $\begin{array}{c}\text { Day } 3 \\
\text { Skills training }\end{array}$ & $\begin{array}{ll}\text { Skills Taught } \\
\text { - } & \text { Propulsion pattern forward and } \\
\text { - } & \text { backwards } \\
- & \text { Thelieving weight } \\
- & \text { Doors } \\
- & \text { Tight spaces/spatial awareness } \\
- & \text { Folding and unfolding chair }\end{array}$ \\
\hline $\begin{array}{c}\text { Day } 4 \\
\text { Training evaluation }\end{array}$ & $\begin{array}{ll}\text { - } & \text { WST } \\
\text { - } & \text { Review goals }\end{array}$ \\
\hline
\end{tabular}

\subsubsection{Training Program Evaluation}

A quantitative approach was used to measure the impact of wheelchair skills training on participants' skills performance; the predictor was the provision of the training program.

Baseline Data

On Day 1 of the training program, baseline data were gathered about children's current skills and their goals in collaboration with the wheelchair skills trainer, who was a physiotherapist. The Wheelchair Skills Test (WST) was used to evaluate the effectiveness of the wheelchair skills training program. The WST version 5.0 was used to establish children's baseline skill levels and, later, the impact of training [37,57-59]. The WST is an objective observational performance-based measure and standardized evaluation method designed for adults. It includes a set of representative wheelchair skills [37,38,59-61]. Children were assessed using the first thirteen skills in the WST (see Figure 2). No adaptations were made to skills being tested, and participants negotiated skills while following the WST 5.0 script during the assessment stage [59]. The occupational therapy student recorded the children's performance and discussed this with the trainer to ensure scores were recorded accurately. 
Table 2. Questions used to guide focus groups.

\section{Focus Group 1}

- To start, I would like you all to introduce yourself, whether it is your daughter or son who is partaking in the Wheelchair Skills Training Program (WSTP), how old your child is and how log your child has been using their wheelchair.

- I would like you all to take a moment to think back to this morning - how did you feel when bringing your child to participate in the programme?

- How would you rate your current understanding of wheelchair skills?

- Why do you feel partaking in the wheelchair skills training programme is important?

- What do you hope to get out of participating in the programme- both for you and your child?

Focus Group 2

- $\quad$ Photovoice (cue participatory action research - PAR). Discuss photographs presented.

\section{Additional Focus Group Questions}

- Was the WSTP what you were expecting it to be, or were there any elements you learned that surprised you?

- What were the best points of the program delivery?

- How do you feel as a parent you have benefited from partaking in the WSTP?

\section{Wheelchair Skills Test (WST) Version 5.0 Form}

Manual Wheelchairs

Name of wheelchair user:

Caregiver assisting (if any):

Tester:

$$
\text { Date: }
$$

\begin{tabular}{|c|l|c|l|}
\hline$\#$ & \multicolumn{1}{|c|}{ Individual Skill } & $\begin{array}{c}\text { Capacity } \\
(\mathbf{0 - 3})^{*}\end{array}$ & Comments \\
\hline 1 & Rolls forward short distance & & \\
\hline 2 & Rolls backward short distance & & \\
\hline 3 & Stops on command & & \\
\hline 4 & Turns in place & & \\
\hline 5 & Turns while moving forward & & \\
\hline 6 & Turns while moving backward & & \\
\hline 7 & Maneuvers sideways & & \\
\hline 8 & Picks objects from floor & & \\
\hline 9 & Relieves weight from buttocks & & \\
\hline 10 & Performs level transfers & & \\
\hline 11 & Folds and unfolds wheelchair & & \\
\hline 12 & Gets through hinged door & & \\
\hline 13 & Rolls longer distance & & \\
\hline
\end{tabular}

Figure 2. The Wheelchair Skills Test (WST) administered to participants. * General Scale for Scoring Skill Capacity (0) Fail (1) Partial Pass (2) Pass (3) Advanced Pass.

Following the completion of the WST, the WST-Questionnaire was chosen as a subjective self-report measure rating capacity, confidence and performance by the parents on their child's confidence and ability to perform the skills prior to and after the skills training (details are not included in this paper). The trainer and occupational therapy student then collaborated with the children and parents to establish individual goals for the program. Safety and intervention goals were also established.

Safety: To prevent the risk of participants falling, tipping or losing control, spotter straps were attached to all wheelchairs with the trainer acting as a spotter for all skills performed during the testing and training sessions.

Intervention: Training sessions were facilitated by a qualified physiotherapist with the support of an experienced wheelchair user. Children participated in four, one-hour 
individual training sessions over a five-week period. Trainers followed the training script and set-up to help guide sessions, including playing a game to keep the children engaged. Children were encouraged to practice the skills at home with their parents. During training sessions, parents/guardians learned about the safe practice of skills (see Table 1 for intervention overview).

\section{Evaluation Data}

On Day 4 of the training program, parents returned the open-ended questionnaires evaluating the wheelchair skills information pack that they had received on Day 1.

Children and parents repeated the WST, and individual goals were reviewed for each child.

Participants used WhatsApp to send photographs to a research smartphone; these photographs were transferred to the researcher's computer via Desktop WhatsApp. WhatsApp was selected to send images due to its secure end-to-end encryption [62]. Photos were deleted from this source once retrieved.

Parents participated in the second focus group to discuss Photovoice data. They shared their photographs and photo narratives, facilitating discussion on the wider benefits of participating in and evaluating the program. This focus group was conducted by a moderator and facilitated by an assistant who took notes. The moderator encouraged interactions between participants [52,63]. A PowerPoint presentation and projector displayed participants' images. A topic guide was developed to keep the discussion focused [56,63]. The session was audio recorded, finishing when data saturation was achieved, and no new ideas emerged [64]. As part of method triangulation [65], the moderator and assistant discussed their notes about key points. A reflective diary was used to reduce research bias and increase transparency during the collection and analysis of data [66].

\subsection{Data Analysis}

Several types of data were collected during this study. Quantitative data included demographics, and pre- and post-WST scores. Qualitative data included results of the focus groups and open-end questionnaire.

Due to the small sample size, quantitative data were analyzed using Microsoft Excel, and data were presented graphically using the Excel chart function. Pre-/post-WST test scores were compared to measure the improvement of skills. Questionnaires were analyzed using content analysis, a descriptive qualitative approach to identify themes based on frequency of occurrence $[67,68]$.

The theoretical perspective of constructivism was selected to explore the ontology, epistemology and characteristics of the thematic analysis, which relate to the daily actions individuals carry out and the dynamic process of creating meaning through experience while situated within a social and cultural context [69]. This perspective can help to understand attitudinal, mobility and participation barriers from the parent's perspective, and how these influence social "norms" associated with disability, ability and quality of life.

Audio recordings of each focus group were transcribed verbatim [69] using Transcription Buddy software (Express Scribe Transcription Software for Windows, NCH Software Inc, Greenwood Village, CO, USA). Thematic analysis (TA) was selected, providing an in-depth account of complexities found within data [69,70]. Braun and Clarke's six-phase model for TA was applied to formulate and interpret themes, using NVIVO software (NVIVO 12, QSR international, Burlington, MA, USA) analytic note keeping and thematic mapping $[69,71]$. The six-phase TA model is summarized in Table 3. Participants received a copy of the results via email for member checking [69], ensuring participant views and experiences were accurately captured and represented in line with Photovoice method objectives. All participants agreed with the findings. 
Table 3. Six phase TA model.

\begin{tabular}{|c|c|}
\hline Thematic Analysis (TA) Stage & Details \\
\hline 1. Familiarization and data immersion & Transcripts were read several times, and a list of ideas about the dataset was compiled. \\
\hline 2. Generating initial codes & $\begin{array}{l}\text { The dataset was coded, with a focus on codes that addressed the research question } \\
\text { and objectives. }\end{array}$ \\
\hline 3. Searching for themes & $\begin{array}{l}\text { Candidate themes were derived-concepts, topics and issues were highlighted, and } \\
\text { each code was revisited to identify similarities and overlap that could be used as a } \\
\text { central organizing concept. }\end{array}$ \\
\hline 4. Reviewing themes & $\begin{array}{l}\text { Codes selected for each theme were revisited to ensure representativeness. The } \\
\text { datasets were re-read to ensure selected themes represented the entire dataset as it } \\
\text { relates to the research aim and objectives. }\end{array}$ \\
\hline 5. Naming and defining themes & $\begin{array}{l}\text { Each theme was named and defined by outlining its key features and what is specific } \\
\text { to its data. }\end{array}$ \\
\hline 6. Writing the results & $\begin{array}{l}\text { Under each theme, extracts from the data were selected to best illustrate the key points } \\
\text { that represented each theme. The results were written using an analytical approach, in } \\
\text { which content is closely tied with the extracts presented. }\end{array}$ \\
\hline
\end{tabular}

\subsection{Ethics}

The Faculty of Education and Health Sciences, Research Ethics Committee of the University of Limerick (EHSREC No: 2019_05_23_EHS), approved the project design.

Participants received information letters and completed consent/assent forms. Participants could refuse participation or withdraw from the study [72]. Photographs were retrieved from a research smartphone, approved by the Ethics Committee [69], and stored at the university. Data were stored on password-protected computers and were anonymized; all identifiers were replaced by pseudonyms, and faces were blurred in photographs to ensure participant confidentiality and anonymity [73-75].

\section{Study Findings}

Quantitative findings include demographic data, and pre- and post-WST data. Qualitative findings include content analysis of the results from the evaluation of the wheelchair skills training information pack evaluations, and Photovoice focus group data. Study findings are presented, first by demographic data, and then by the four study objectives.

\subsection{Demographic Data}

Four children and their parents participated in the study. One child who was 2.5 years old was included in the study on the specific request of his parents. The mean age of participants was 5.6 years old. Participant characteristics are presented in Table 4.

\subsection{Objective 1: Evaluation of the Wheelchair Skills Training Information Pack}

Responses from the wheelchair skills information pack open-ended questionnaire demonstrated its usefulness and the likelihood of continued use at home. Parents considered the information pack "very useful" (3) or "useful" (1), and agreed with the statement that they would continue to use the pack at home after the study. Most parents recommended further developing the information pack and making it available online or as an app.

Three categories and themes were created using Analogue Content Analysis [72] These include (1) "A beneficial experience", (2) "Information pack content" and (3) "Future Recommendations", as outlined in Table 5. 
Table 4. Participant characteristics.

\begin{tabular}{|c|c|c|}
\hline Pseudonym Names (Parent/s) & Pseudonym Names (Child) & Age of Child at Time of Program (Years) \\
\hline Elaine & Sally & 8 \\
\hline Emily & Joanne & 5 \\
\hline John and Liz & Jackie & 7 \\
\hline Aine & James & 2.5 \\
\hline mean $(\min -\max )$ & & $5.6(2.5-8)$ \\
\hline \multicolumn{3}{|c|}{ Ethnicity } \\
\hline Irish & & 4 \\
\hline Other & & 0 \\
\hline \multicolumn{3}{|c|}{ Sex } \\
\hline Male & & 1 \\
\hline Female & & 3 \\
\hline \multicolumn{3}{|c|}{ Mobility Aid Use (1+ aids for some children) } \\
\hline Wheelchair (full-time) & & 3 \\
\hline Wheelchair (part-time) & & 1 \\
\hline Walker (full-time) & & 0 \\
\hline Walker (part-time) & & 1 \\
\hline Braces (full-time) & & 1 \\
\hline Braces (part-time) & & 0 \\
\hline
\end{tabular}

Table 5. Themes of the analogue content analysis.

\begin{tabular}{|c|c|c|c|c|}
\hline Code & Theme & $\begin{array}{c}\text { Frequency of } \\
\text { Code }\end{array}$ & $\%$ Frequency & Illustrative Quotes \\
\hline $\mathrm{T} 1$ & $\begin{array}{l}\text { A beneficial } \\
\text { experience }\end{array}$ & 18 & $60 \%$ & $\begin{array}{l}\text { "Everything that ye have done and the advice given has made } \\
\text { such a difference for us, for Joanne" [Emily] } \\
\text { "Knowing how to do things the right way to make life easier on } \\
\text { themselves" [John] }\end{array}$ \\
\hline $\mathrm{T} 2$ & $\begin{array}{l}\text { Information pack } \\
\text { contents }\end{array}$ & 3 & $10 \%$ & $\begin{array}{l}\text { "... I think it is a good book. The photos are especially useful } \\
\ldots \text { ". [John] } \\
\text { "We found this course so helpful making life easier for Joanne } \\
\text { and us" [Emily] }\end{array}$ \\
\hline $\mathrm{T} 3$ & $\begin{array}{l}\text { Future Recom- } \\
\text { mendations }\end{array}$ & 9 & $30 \%$ & $\begin{array}{l}\text { "In time it could be expanded to include video links to demos" } \\
\text { [Aine] } \\
\text { "Video tutorials of the skills that were stored online } \\
\text { somewhere/app" [Elaine] }\end{array}$ \\
\hline
\end{tabular}

\subsection{Objective 2: Pre-/Post-Wheelchair Skills Test (WST) Findings}

Analysis of pre-/post-WST scores showed an overall improvement amongst all participants, as depicted in Figure 3. A higher score in the post-WST indicated increased skill development. In-depth analysis of individual scores showed a decreased post-WST score for some skills performed by participants.

Analysis of the Photovoice data revealed two primary themes, as illustrated in Table 6. These themes respond to Objectives 3 and 4 of the study:

To explore parents' perspectives on how training had influenced children's daily participation.

To identify beneficial aspects of program delivery for children and parents. 


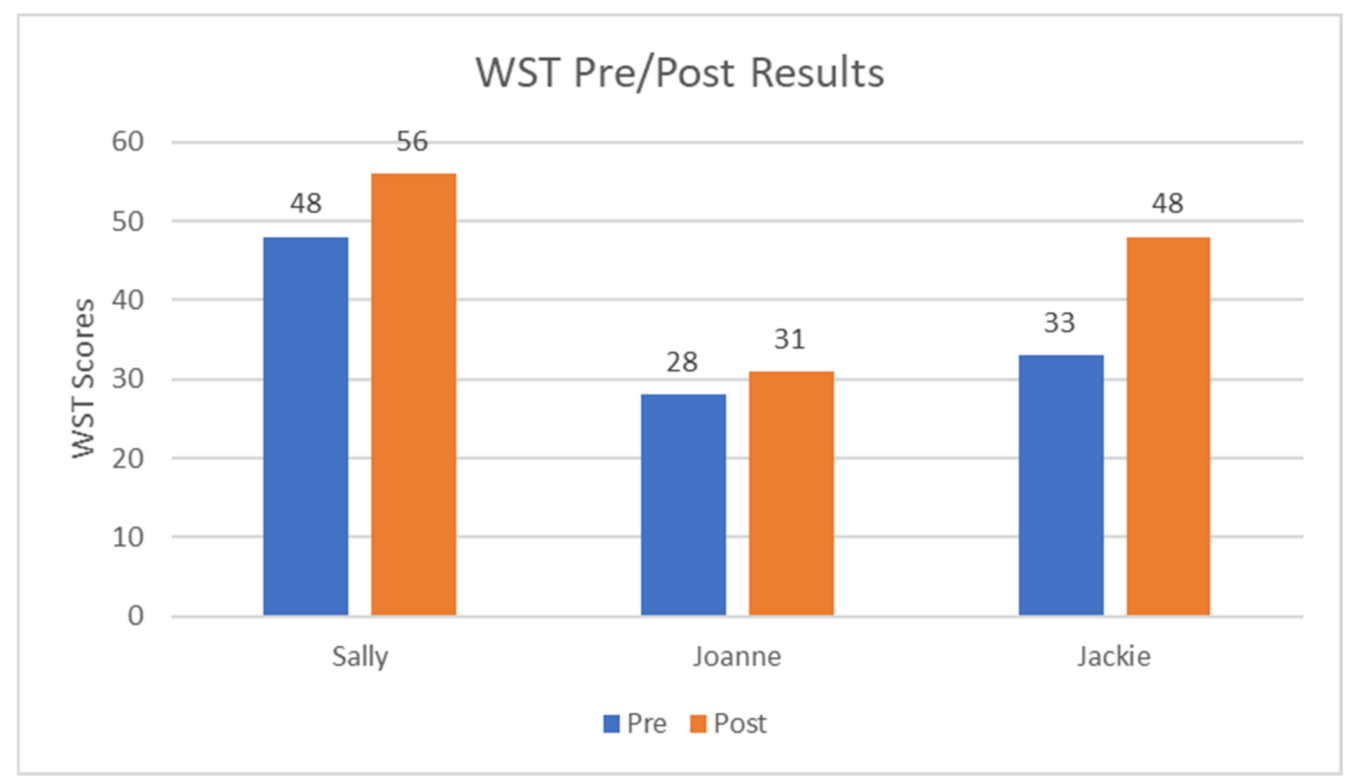

Figure 3. Pre-/post-WST results.

Table 6. Photovoice thematic overview.

\begin{tabular}{|c|c|}
\hline Post-Wheelchair Skills Training Program & Thematic Overview \\
\hline $\begin{array}{l}\text { (T1) Parents' Perspectives on how Training } \\
\text { Influenced Children's Daily Participation }\end{array}$ & $\begin{array}{ll}\text { - } & \text { Individual goals and training sessions } \\
\text { - } & \text { Exposure to an experienced wheelchair } \\
\text { - } & \text { user (positive role model) } \\
\text { - } & \text { Increased confidence } \\
\text { - } & \text { Greater independence } \\
\text { - } & \text { Greater levels of participation }\end{array}$ \\
\hline (T2) Beneficial Aspects of Program Delivery & $\begin{array}{l}\text { - } \quad \text { Parental observation of training sessions } \\
\text { - } \\
\text { - } \quad \text { Orill developercoment support and reinforcement of } \\
\text { - } \quad \text { Benefits of early intervention } \\
\text { - } \quad \text { Parental frustration with current } \\
\text { wheelchair provision services }\end{array}$ \\
\hline
\end{tabular}

3.4. Objective 3: Parents' Perspectives on How Training Influenced Children's Daily Participation

This theme encompassed parents' experiences of skill development. Photographs illustrated increased confidence, safety, independence and levels of participation.

Parents highlighted how individual training sessions contributed to the gains made by children.

"Obviously again they are all at different ages and stages and abilities and all the rest of it. I thought the one-on-one was brilliant."-Aine

Having an experienced wheelchair user deliver training contributed to increased motivation and reassurance experienced amongst children and parents alike.

"It is always great to see someone who can use their wheelchair independently and I think it is great for kids to see that, you know, to see that ..., you can just go and do it."-Elaine

\subsubsection{Photovoice T1 Findings: Elaine and Sally}

Following completion of the pre-WST, Sally showed a strong baseline skillset, with certain areas requiring further training and practice. Sally was able to do wheelies, but only 
when shown during training did she learn how to use this skill in practice. Elaine selected two photographs, within two different contexts, that illustrated the benefits of this skill.

Elaine narrated the photo in Figure 4 as follows:

"Sally would have just driven at the step and forced the chair over it with a risk of damaging the chair and getting hurt herself; she is now able to roll her chair backwards and forwards to navigate changes in level."

Elaine explained how, in the past, the natural terrain illustrated in Figure 5 would have proved difficult for Sally. Developing her skillset allowed her greater independence while safely navigating more challenging environments.

"I was amazed - really we went a good distance into the forest ... she was able to do it herself, doing the tip back and forward to get over the bed and bits of roots sticking over the ground."-Elaine

Although Sally achieved most of the goals identified at the start of the program, improvements for some skills were not reflected in her post-WST results. Maneuvering sideways was a skill Sally improved, but this was not reflected in her post-WST score. When rolling backwards, Sally looked over one shoulder only. To obtain a higher mark, she would have needed to look over both shoulders. Sally did not have the strength to fold and unfold her wheelchair, resulting in a zero score for that criterion.

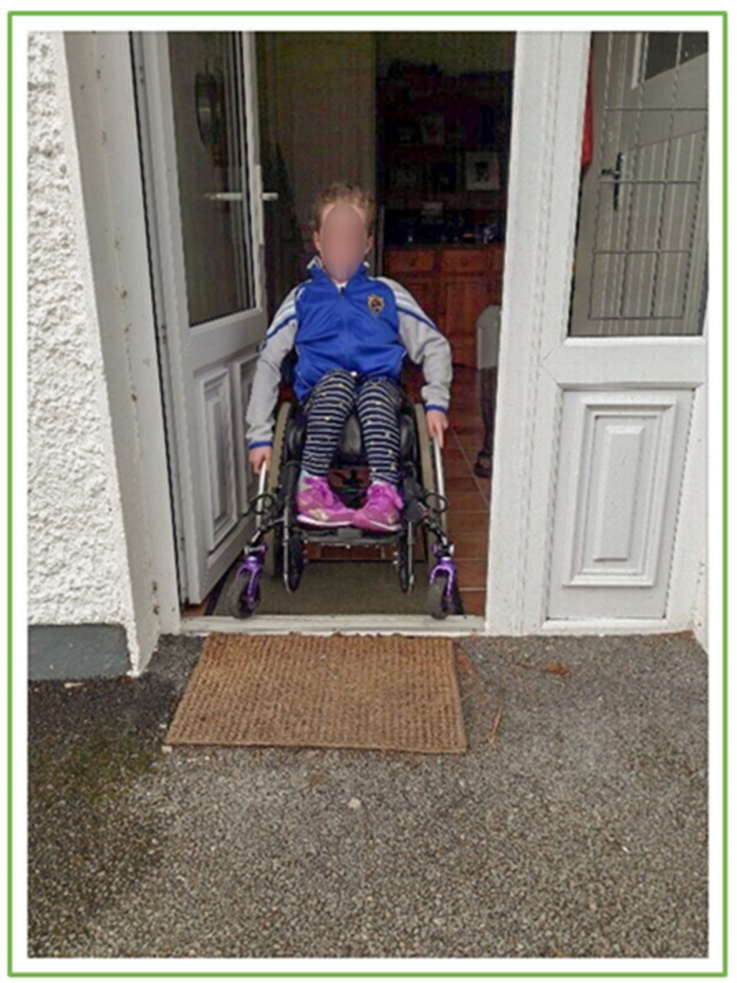

Figure 4. Navigating the slight step at the back door. 


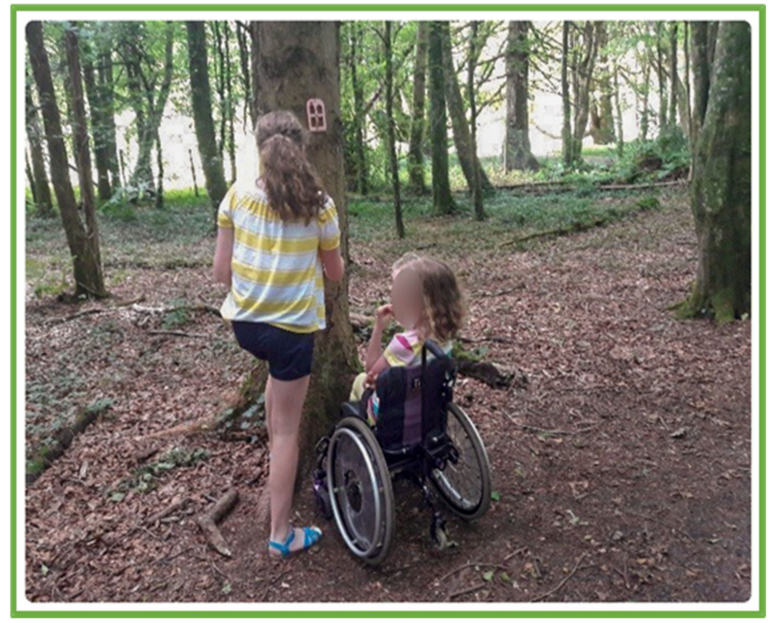

Figure 5. Sally and her cousin on a fairy forest trail.

\subsubsection{Photovoice T1 Findings: Emily and Joanne}

Joanne had an appropriate baseline skillset for her developmental stage. During training sessions, Joanne required additional time to process the skills using visual prompts to help her comprehension for safe performance. Emily described exposure to training as motivating for Joanne to practice her skills at home:

"She was determined to do it and was not happy until she succeeded."

One of Joanne's goals was to independently open and close doors while navigating her wheelchair, and an improvement in this skill was observed following training. Developing this skill increased her independence at home, and introduced a new dimension of playfulness, as illustrated in Figure 6. Emily narrated:

"Now she just disappears in the house at times; she would be gone into one of the rooms and hiding."

Joanne also improved her level transfers skills. She required age-appropriate moderate assistance to complete the skill. However, due to the specificity of the WST, this improvement could not be recorded. Joanne was unable to pick up objects from floor level due to her wheelchair height, thus resulting in a zero WST score for this skill. Joanne did not have the strength to fold and unfold her wheelchair, also resulting in a zero score.

\subsubsection{Photovoice T1 Findings: Jackie}

Jackie's baseline skillset was appropriate for her developmental stage, but she required additional development for safer execution. Jackie's post-WST scores showed the greatest improvement after completion of the program. One of Jackie's goals was to independently and safely complete level transfers, which she achieved following training. This skill is discussed by John and Liz and depicted in Figure 7.

John described how Jackie previously carried out level transfers:

"She would drive the wheelchair straight up and kind of throw herself out."

John described her as now being able to:

"Pop out of the wheelchair"

These narratives indicated that transfers were no longer a struggle. This development boosted Jackie's confidence, as John narrated:

"When she got the transfer right, she was pure delighted with herself."

The wheelchair prescribed to Jackie was observed to be ill-suited to her needs; it led to her having a propulsion pattern that used a lot of her energy. Jackie's wheelchair did not fold or unfold and resulted in a score of zero for both pre- and post-WST. 


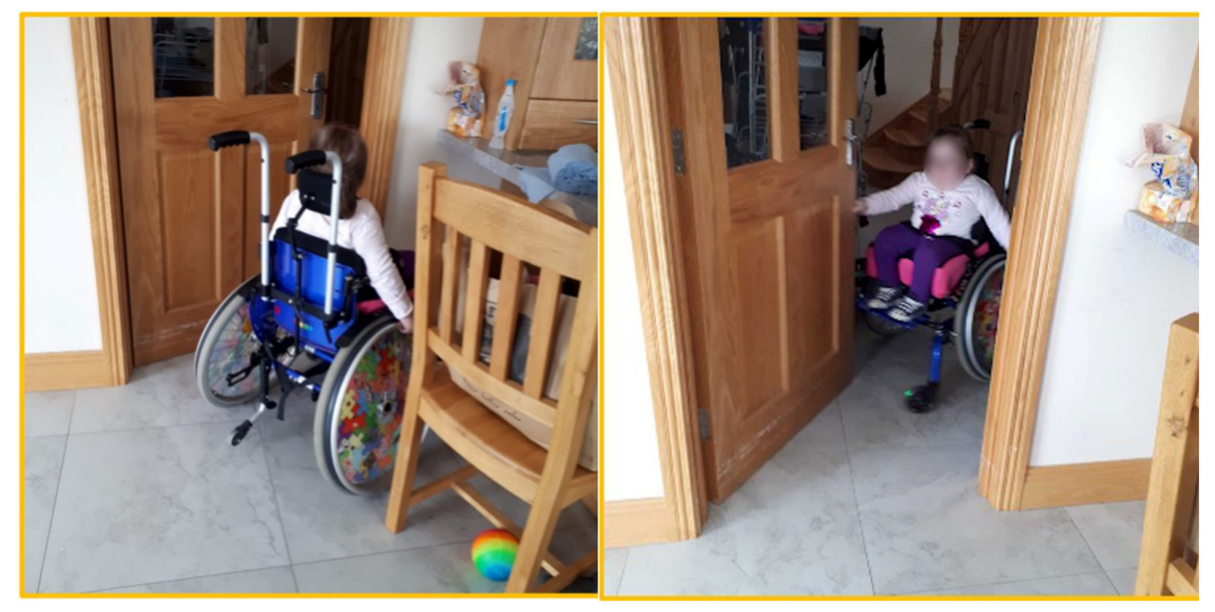

Figure 6. Opening and closing the door by herself.

\subsubsection{Photovoice T1 Findings: Aine and James}

James, aged 2 years and 6 months, was the youngest participant on the program and could not follow the formal structure of the WST and training. Bespoke training (illustrated in Table 7) was conducted following the same skills of the program along with parent education. Aine described their experience as having:

"contributed to giving him the right patterns from a very early age, that you know he will build on those."
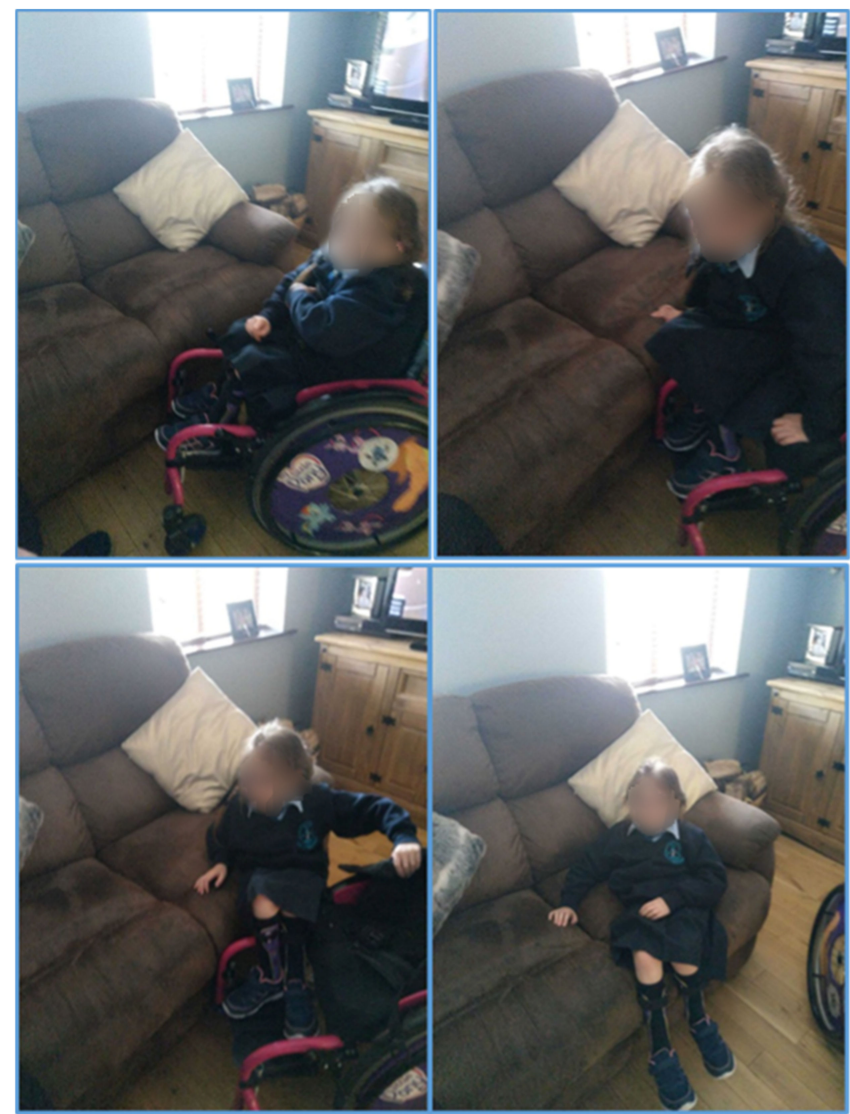

Figure 7. Jackie is transferring from her wheelchair to the couch following the steps provided. 
Table 7. Bespoke training for James.

\begin{tabular}{cc}
\hline Skill & Comment and Plan \\
\hline Rolling Forward (second session) & Follow the leader \\
\hline Rolling backward (second session) & Follow the leader \\
\hline Object negotiation (second session) & Mats set up to drive through \\
\hline Reaching (second session) & Ball/bean bag toss \\
\hline Turning (second session) & Navigating tight spaces (not sideways) \\
\hline Object manipulation (third session) & $\begin{array}{c}\text { Basketball—hold ball with one hand and } \\
\text { propell with the other, then alternate }\end{array}$ \\
\hline Forward propulsion (third session) & Choo choo train—emphasized leaning forward \\
\hline Turns in circle (third session) & Chasing Dad forward and around trainer \\
\hline Navigating tight spaces (third session) & Forward only through obstacles-90 $/ 180^{\circ}$ \\
turns
\end{tabular}

James improved spatial awareness and developed insight into how to use his body weight to accomplish skills. Aine narrates the activity in Figure 8:

"Leaning forward going up the hill-he is doing that and even coming down the hill he will say 'lean back', so he is saying it and doing it."

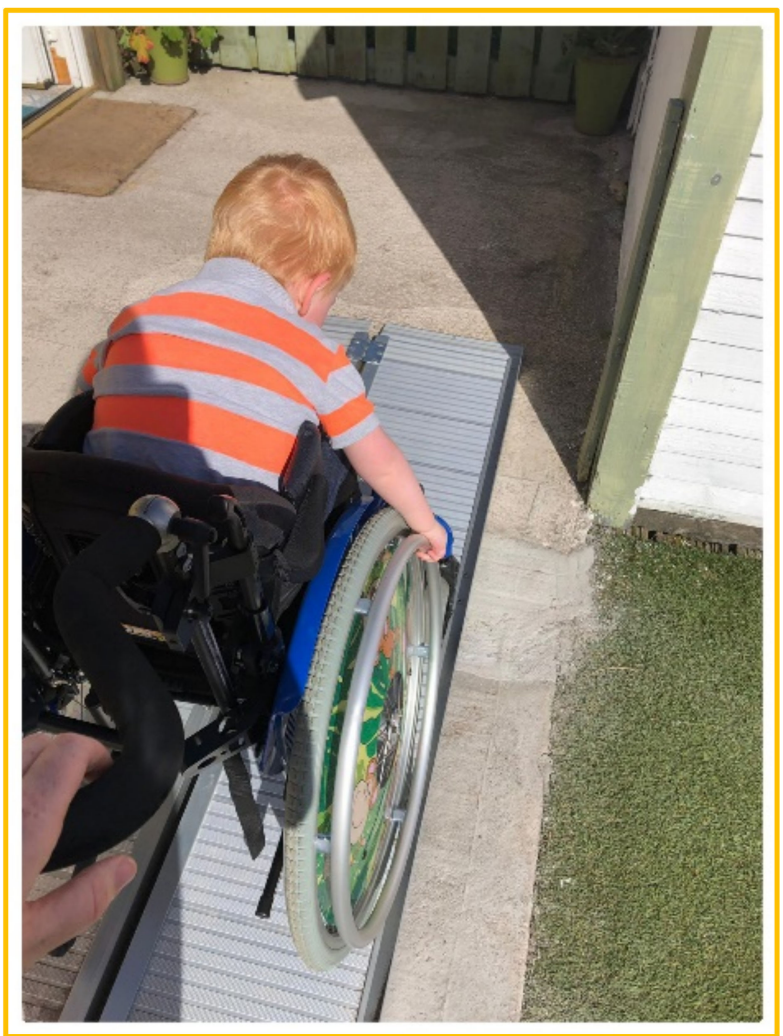

Figure 8. Practicing his skills-leaning forward going up a slope.

Even though he could not follow the full program, some of the goals set for the training were met, such as parent education, thresholds, strategies and inclines. Given his age, James did not achieve his level transfer goal during the training. 


\subsection{Objective 4: Beneficial Aspects of the Program}

This theme includes aspects of learning and developing new skills, overcoming badhabits, early exposure, parental support for skill development and frustration with current wheelchair provision.

Parents reported that the observation of training sessions was beneficial and allowed them to support their child's learning.

"She could see, and I could see, so when we are at home, I could say, so remember when (instructors name) did X, Y, Z. I think that was the best part of it."-Elaine

During the discussion, parents described how skills were correctly carried out. Parents referred to guiding and reinforcing correct methods while their child practiced at home to overcome bad habits. Liz narrates the activity in Figure 9.

"We are trying to get her to lift the wheels to come in over it, but she is not really getting that one yet, but we will keep trying" - Liz

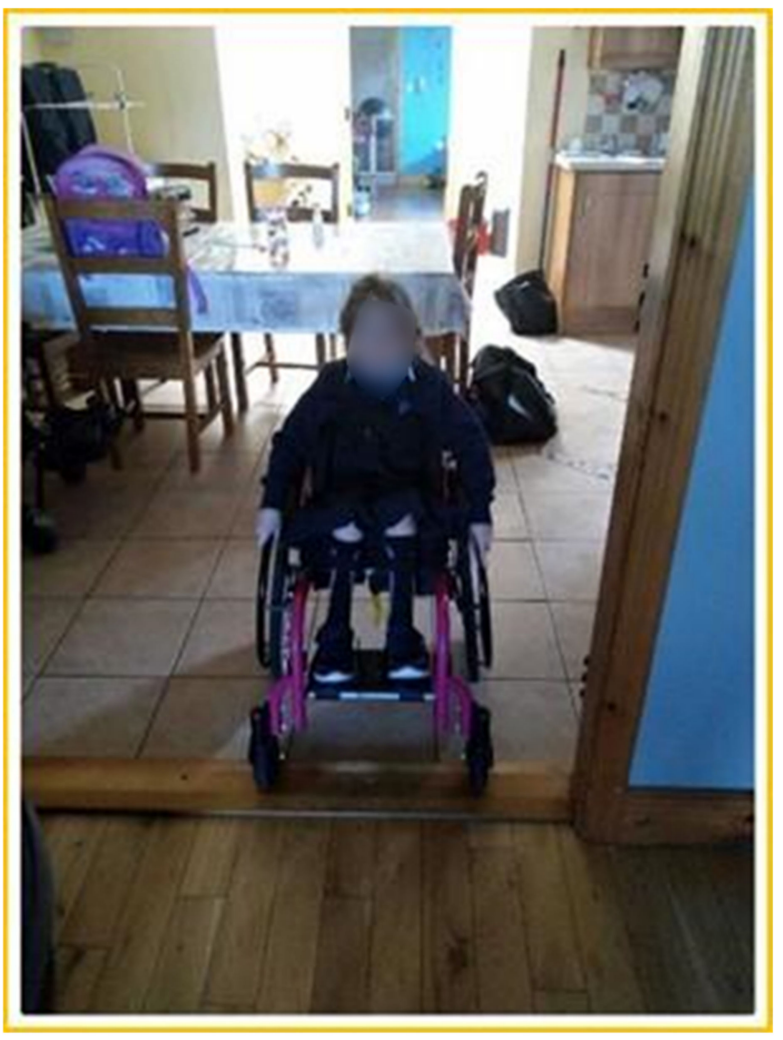

Figure 9. Jackie going into the sitting room.

Similarly, Elaine narrated the same reinforcement of skills for Sally when practicing her long pushes, as depicted in Figure 10.

"It will take some time for this habit to be fully adopted as she is used to wheeling herself as fast as her arms allow."-Elaine

Parents felt frustration with current wheelchair provision, and the lack of available training and educational resources, as explained in these quotes:

"As long as they are just sitting properly in it, it's like alright so see you later, off you pop ... we have no experience with using a wheelchair or anything, so we were like right ... okay, that's it (after James received his wheelchair)."-Aine

"Figure out how to use it yourself" - Liz 

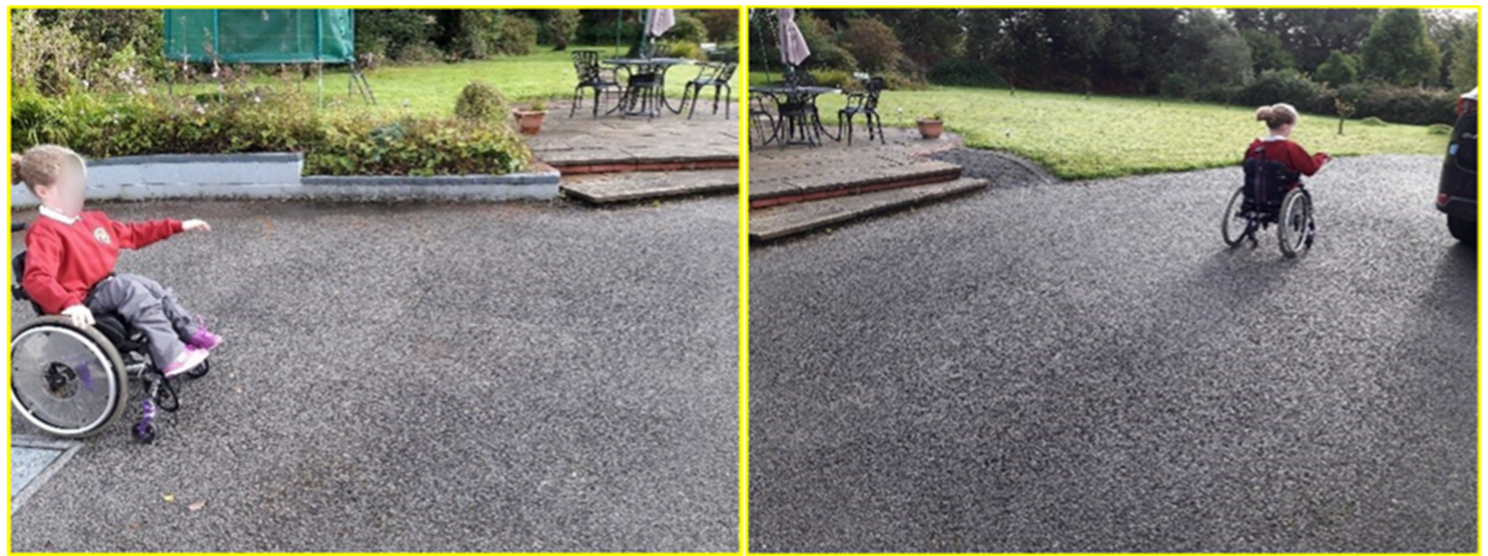

Figure 10. Sally learning to wheel more freely.

Without resources, parents can only support children to the best of their own knowledge. Liz described how Jackie was previously carrying out level transfers,

"The way Jackie was hopping across to the couch was dangerous like, but sure we never knew that."

In Focus Group 2, parents made recommendations for service delivery based on their experiences, including a two-part program.

Part (1)_“"Targeted towards younger children when first given their wheelchair, to inform good habits from the start"-Aine

Part (2)_" At a later stage, when children are older and ready to advance their skillset further."-Elaine

\section{Discussion}

This pilot study was successful in achieving its objectives. The evaluation of the program produced encouraging results and contributed to recommendations. Parents found the whole program to be a beneficial experience. They found the information pack to be useful and educational, and they provided feedback on ways to enhance the information pack. In addition, the analysis of the pre-/post-WST showed that all participants improved their wheelchair skills post-training. The Photovoice narrative descriptions illustrated that children experienced increased confidence, safety, independence and participation, and reiterated to parents the benefits of the program.

\subsection{Interpretation of Findings}

\subsubsection{A Beneficial Experience}

Prior to participating in the pilot program, parents described their uncertainty about wheelchair skills and their inability to access appropriate wheelchair skills training education and materials for their children. Growing evidence highlights the importance of providing family services that build upon parental capacity for sustainable interventions that support optimal child outcomes $[33,34,76]$. All parents noted that the information pack was beneficial for them and their children, as it was seen as a useful and educational resource. The information pack provided parents with additional supportive education in addition to the direct intervention for their children. The aim of this program was to build on parents' knowledge of wheelchair skills to enable them to support their children's learning and development of skills between sessions and in the home environment.

\subsubsection{Information Pack Content}

When asked what could be added to the information pack to make it more user friendly for children, parents recommended incorporating images of children demonstrating the 
wheelchair skills. Observing success in a peer of a similar age has been noted in research as a strategy used to promote self-efficacy [77]. Thus, increasing motivation while allowing children to connect more easily with the content is an important goal of such interventions.

\subsubsection{Future Recommendations}

Parents acknowledged the importance of early intervention and the need for appropriate information on wheelchair skills to support their children to use their wheelchairs safely. Wheelchair-user behavior and its association with wheelchair accidents is well documented [20,78]. Physical and psychosocial consequences of falls are significant [79], negatively impacting activity, social participation and quality of life $[20,78]$. Without education, these issues can negatively impact children's self-efficacy, confidence and independence, particularly at critical stages of early development. The study findings suggest that families may benefit from an information pack such as this when receiving a first-time wheelchair.

Most parents recommended further developing the information pack and making it available online or as an app. Mobile health, commonly referred to as mHealth, relates to medical and public health practice supported by mobile devices that include applications or apps [80]. The widespread use of smartphone and tablet technology offers healthcare professionals new directions to consider when developing resources and interventions that can better support family needs [33,49,80-82]. Advantages of further developing the information pack as a mobile app include its potential to make content widely accessible amongst targeted populations [80], while incorporating multimedia channels such as text, illustrations, video and graphics. Such multimedia engagement would support a learning experience that can improve knowledge transfer by catering to a user's multisensory learning style, offering the potential for more in-depth learning $[49,83]$.

In response to existing barriers for accessible and appropriate wheelchair education, one study developed and investigated the use of a "My Wheelchair Guide" app targeted towards adults [49]. The aim of the app was to improve users' knowledge by consolidating information on wheelchair use and service delivery to encourage individuals to advocate for their own seating and mobility needs. Findings indicated that the app alone was not adequate to improve the wheelchair fit/set-up and wheelchair users' skills, acknowledging the need for individualized assessment and training by qualified professionals. However, both participants and clinical professionals recognized that the use of the app may benefit new wheelchair users in broadening their knowledge of the area and learning basic wheelchair skills.

Unlike resources developed for adults [49], the findings of this research also support the need for the training of basic wheelchair skills amongst pediatric populations that account for children's developmental stage and wheelchair suitability. Additional research is needed to investigate the singular impact of an information pack for families and children to better inform future directions and the development of this kind of resource.

Parents reported children demonstrating increased skill acquisition and confidence using their wheelchairs, allowing greater independence, participation and safer engagement in their environments. Parents identified program factors contributing to these gains, such as individual training sessions that accommodated for different stages of development amongst children. The program was also seen to motivate children to practice and develop their skills in the home environment.

The Photovoice results showed the positive impact of training on children's wheelchair use. Additionally, skill development contributed to parents' increased confidence in their children's abilities and capabilities. The analysis of the WST scores showed an overall improvement in skills. (The youngest participant, due to his age and developmental stage, was unsuitable to partake in the WST, but there is evidence that he benefitted from the training.) Despite the improvements, the progress children made in certain skills was not accurately captured in their post-WST scores due to the high skill level required by Kirby's training program [59] to obtain a top score. For instance, the children did not master the skill of folding and unfolding their wheelchairs, probably due to their age and strength 
level. One participant's wheelchair was ill-suited to her needs, preventing her from picking up objects from the floor, and due to its un-foldable nature, led to the participant scoring zero in both skills. Kirby's [59] training program was developed for adult wheelchair users, and the skills selected for training were not adapted for this research.

In a similar study with children, Sawatzky et al. [37] adapted both the training program and the WST 3.2 to a developmentally appropriate level to allow children to achieve higher scores. Additionally, skills that children would not be able to achieve were removed. Huegel et al. [38] recommended general, clinical and relevant considerations that may enhance the use of the WST in children with spina bifida. Sol et al. [84] developed and validated a wheelchair mobility skills outcome measure called the UP-WMST to administer to children. As identified in previous studies, further research is needed to explore wheelchair skills training for children, as well as the development of outcome measures that account for subsets within pediatric populations, to capture a more accurate account of children's individual progress in response to training.

Evidence suggests salient factors of program delivery for children, which include promoting success and a sense of achievement through realistic goal setting and motivational staff [35]. In previous studies, participating in formal community activities has also been seen to allow children to recognize and understand their capabilities, motivating youths to set long-term goals $[85,86]$. The children who participated in this study did not achieve all their goals, but each child made great progress towards attaining them. It is worth mentioning that the goal setting used as part of this study was broad in nature, making it difficult to evaluate whether some goals were achieved or not. It is recommended that future research uses SMART goal setting to better account for children's developmental stages as part of this process [87].

Finally, having an experienced wheelchair user deliver training was impactful for parents and children. The user was seen as a positive role model, demonstrating basic to advanced skills. Mentors who share similar life situations are noted in research as inspirational and motivating for children, helping them to explore limits, and serving as a source of emotional support $[35,85,88]$.

Findings suggest skills take time to learn before being routinely implemented, and parents have an influential role in children's wheelchair skill development. Parents supported their children to practice, learn and develop their skillsets. Parents' critical role in motivating and engaging children to feel ownership for behaviors, while assisting children to apply skills in real-world environments, is widely documented [33-35,76,89]. Parents actively learned how skills were performed while accompanying their children during training sessions, and this was recognized as a key positive aspect. Exposure supported parents to deepen their knowledge and insight, and to gain confidence to be able to support their children in practicing and developing their skills.

The parent of the youngest participant felt that exposure to wheelchair skills training while her son was so young placed her in a better position to support him to continue to experience his wheelchair in a positive way. She perceived early exposure as an opportunity to develop good habits from the start, lowering the risk of fear that other children encountered following accidents. Evidence highlights the importance of early intervention as self-propelled mobility facilitates opportunities for young children to reach their developmental milestones [27] and is critical to child development [29]. Early experiences of independent mobility and environmental exploration accelerate changes in motor planning, cognition, socialization and emotional skills $[29,30]$. In this regard, a shift in patterns of attachment, coping skills and increased self-awareness [31] while immobility can lead to learned helplessness [90]. Early exposure both of parents and children to wheelchair education and training is critical to support long-term positive outcomes and quality of life.

Parents shared feelings of frustration about the delivery of current wheelchair provision services, receiving no support beyond prescription and fitting. The provision of a wheelchair does not guarantee its safe and effective use [18,61]. Rousseau et al. [91] state that a wheelchair reduces the negative impact of physical disability. However, children 
must be able to use the wheelchair effectively. Findings of a study of occupational therapists' perceptions of pediatric manual wheelchair users demonstrates the importance of flexible skills training and training materials in this respect [92]. The current lack of opportunities for education and training may limit the potential impact of receiving a wheelchair on individual and family life. Although the program described here has several benefits, parents outlined program delivery modifications to better meet their needs. Sawatzky et al. [37] made similar recommendations for a staged approach, which considered children's developmental stage and level of ability. The findings from this study support recommendations for further research in this area.

\subsection{Clinical Relevance}

This research supports the creation of family-centered approaches in wheelchair provision services that acknowledge and contextualize the need to provide education and training to meet individual and family needs for children with spina bifida and/or hydrocephalus. In this study, parental recommendations for improved services to meet their needs are supported by research that suggests the benefits of early intervention. This study is relevant to occupational therapists as they are key stakeholders in the provision, training and education of wheelchairs and wheelchair skills.

\subsection{Study Limitations}

There are limitations associated with this study. (1) Generalization is a problem when working in studies with small-sample groups. One of the aims of the research was to investigate parents' perspectives. However, only one co-parenting couple took part. Findings and interpretation could have been strengthened if both parents of each child were involved. However, findings from this study still have the potential to inform future programs. (2) Due to the restricted access to online information and licensing agreements, the grey literature search strategy used when developing the information pack excluded training programs associated with organizations, which could have further informed its design.

\section{Conclusions}

The lack of knowledge and lack of available resources limited parents' ability to support their children to use their wheelchairs safely. Findings demonstrated the positive impact of participating in a short training program for parents and children. Parent-child relationships were central to skill development. This study highlights existing gaps in Irish wheelchair provision services and the need to provide wheelchair education and training as matter of course, to support parents and children across all stages of development.

\section{Implications for Rehabilitation}

This pilot study has the potential to inform the sustainable development of an appropriate wheelchair skills program for children with $\mathrm{SB} / \mathrm{H}$.

- Wheelchair skills training positively impacted children's confidence and capacity to use their wheelchairs, with findings that suggest support for early intervention.

- $\quad$ Parent-child relationships were central to skill development, and parents should be both included and involved during training sessions to secure the transfer of skills at home.

- The information pack provided parents with additional support, and this was positively received. Other benefits of the information pack included its potential for continued and future use by parents and children.

Supplementary Materials: The following are available online at https:/ / www.mdpi.com/article/10 .3390/disabilities2010009/s1, File S1: Wheelchair skills information pack questionnaire.

Author Contributions: Conceptualization, R.J.G.; Data curation, M.B.C., J.M. and E.S.; Formal analysis, M.B.C., J.M. and E.S.; Methodology, R.J.G., M.B.C., J.M. and E.S.; Project administration, R.J.G., M.B.C., J.M. and E.S.; Resources, R.J.G. and Y.C.; Supervision, R.J.G. and Y.C.; Writing—original 
draft, M.B.C., J.M. and E.S.; Writing—review and editing, R.J.G. and Y.C. All authors have read and agreed to the published version of the manuscript.

Funding: Funding for the SBHI wheelchair skills programme was provided by the Early Childhood Ireland, Pyjama Day Fund. Authors did not receive funding to conduct this research.

Institutional Review Board Statement: The study was conducted in accordance with the Declaration of Helsinki, and approved by The Faculty of Education and Health Sciences, Research Ethics Committee of the University of Limerick (EHSREC No: 2019_05_23_EHS).

Informed Consent Statement: Informed consent was obtained from all subjects involved in the study. Written informed consent has been obtained from the patients to publish this paper.

Acknowledgments: The authors would like to thank Spina Bifida Hydrocephalus Ireland (SBHI) for their assistance in the recruitment process and facilitating the venue. The authors would also like to thank the families who participated in the research study and gave their time and willingness to collaborate in the co-production of knowledge, sharing their insight and experiences.

Conflicts of Interest: The authors report no conflict of interest.

\section{References}

1. Rousseau-Harrison, K.; Rochette, A.; Routhier, F.; Dessureault, D.; Thibault, F.; Côte, O. Perceived impacts of a first wheelchair on social participation. Disabil. Rehabil. Assist. Technol. 2012, 7, 37-44. [CrossRef] [PubMed]

2. Rousseau-Harrison, K.; Rochette, A. Impacts of wheelchair acquisition on children from a person-occupation-environment interactional perspective. Disabil. Rehabil. Assist. Technol. 2013, 8, 1-10. [CrossRef]

3. Huang, H.-H. Perspectives on early power mobility training, motivation, and social participation in young children with motor disabilities. Front. Psychol. 2018, 8, 2330. [CrossRef] [PubMed]

4. ICBDSR. Annual Report 2014. Available online: http://www.icbdsr.org/wp-content/annual_report/Report2014.pdf (accessed on 22 November 2021).

5. SBHI. What Is Spina Bifida? 2020. Available online: https://www.sbhi.ie/information/post/what-spina-bifida (accessed on 24 February 2019).

6. SBHI. What Is Hydrocephalus? 2020. Available online: https://www.sbhi.ie/information/post/what-hydrocephalus (accessed on 24 February 2020).

7. Atta, C.A.M.; Fiest, K.M.; Frolkis, A.D.; Jette, N.; Pringsheim, T.; St Germaine-Smith, C.; Rajapakse, T.; Kaplan, G.G.; Metclalfe, A. Global birth prevalence of Spina Bifida by folic acid fortification status: A systematic review and meta-analysis. Am. J. Public Health 2015, 106, e24-e34. [CrossRef] [PubMed]

8. NHS. Ventriculomegaly 2020. Available online: https://www.gosh.nhs.uk/conditions-and-treatments/conditions-we-treat/ ventriculomegaly / (accessed on 21 February 2020).

9. Pit-ten Cate, I.M.; Kennedy, C.; Stevenson, J. Disability and quality of life in spina bifida and hydrocephalus. Dev. Med. Child Neurol. 2002, 44, 317-322. [CrossRef]

10. Kahle, K.T.; Kulkarni, A.V.; Limbrick, D.D., Jr.; Warf, B.C. Hydrocephalus in children. Lancet 2016, 387, 788-799. [CrossRef]

11. Reed, K.L. Quick Reference to Occupational Therapy, 2nd ed.; Pro-Ed, Inc.: Austin, TX, USA, 2001.

12. Lidal, I.B.; Lundberg Larsen, K.; Hoff, M. 50 years and older-Born with spina bifida: Participation, health issues and physical function. Disabil. Rehabil. 2021, 43, 241-250. [CrossRef] [PubMed]

13. World Vision. The 8 Steps+, the Role of Community Development Organizations in Providing Holistic Wheelchair Services 2012. Available online: https:/ /www.worldvision.org/wp-content/uploads/The-8Steps-FINAL.pdf (accessed on 22 November 2021).

14. Gowran, R.J.; Casey, J.; Daly, J. Utilising a Sustainable Community of Practice Model to build best practice in Wheelchair Provision on the Island of Ireland. In Occupational Therapy without Borders: Integrating Justice with Practice, 2nd ed.; Pollard, N.S.D., Ed.; Elsevier: Amsterdam, The Netherlands, 2017.

15. Routhier, F.; Kirby, R.L.; Demers, L.; Depa, L.; Thompson, K. Efficacy and retention of the French-Canadian version of the Wheelchair Skills Training Program for manual wheelchair users: A randomized controlled trial. Arch. Phys. Med. Rehabil. 2012, 93, 940-948. [CrossRef] [PubMed]

16. Morgan, K.A.; Engsberg, J.R.; Gray, D.B. Important wheelchair skills for new manual wheelchair users: Health care professional and wheelchair user perspectives. Disabil. Rehabil. Assist. Technol. 2017, 12, 28-38. [CrossRef] [PubMed]

17. Kirby, R.L.; Ackroyd-Stolarz, S.A.; Brown, M.G.; Kirkland, S.A.; MacLeod, D.A. Wheelchair-related accidents caused by tips and falls among noninstitutionalized users of manually propelled wheelchairs in Nova Scotia. Am. J. Phys. Med. Rehabil. 1994, 73, 319-330. [CrossRef] [PubMed]

18. Xiang, H.; Chany, A.M.; Smith, G.A. Wheelchair related injuries treated in US emergency departments. Inj. Prev. 2006, 12, 8. [CrossRef] [PubMed]

19. Nicholson, J.; Bonsall, M. Powered Mobility for Children under five years of ge in England. Br. J. Occup. Ther. 2002, 65, 291-293. [CrossRef] 
20. Jones, M.A.; McEwen, I.R.; Hansen, L. Use of power mobility for a young child with spinal muscular atrophy. Phys. Ther. 2003, 83, 253-262. [CrossRef]

21. Fernandes, T. Independent mobility for children with disabilities. Int. J. Ther. Rehabil. 2006, 13, 329-333. [CrossRef]

22. Kelly, E.H.; Altiok, H.; Gorzkowski, J.A.; Abrams, J.R.; Vogel, L.C. How does participation of youth with spina bifida vary by age? Clin. Orthop. Relat. Res. 2011, 469, 1236-1245. [CrossRef] [PubMed]

23. Fischer, N.; Church, P.; Lyons, J.; McPherson, A.C. A qualitative exploration of the experiences of children with spina bifida and their parents around incontinence and social participation. Child Care Health Dev. 2015, 41, 954-962. [CrossRef] [PubMed]

24. Bloemen, M.A.T.; van den Berg-Emons, R.J.G.; Tuijt, M.; Nooijen, C.F.J.; Takken, T.; Backx, F.J.G.; Vos, M.; deGroot, J.F. Physical activity in wheelchair-using youth with spina bifida: An observational study. J. NeuroEng. Rehabil. 2019, 16, 9. [CrossRef] [PubMed]

25. Anderson, D.; Campos, J.; Witherington, D.; Dahl, A.; Rivera, M.; He, M.; Uchiyama, I.; Barbu-Roth, M. The role of locomotion in psychological development. Front. Psychol. 2013, 4, 440. [CrossRef]

26. Hoenig, H.; Landerman, L.R.; Shipp, K.M.; George, L. Activity restriction among wheelchair users. J. Am. Geriatr. Soc. 2003, 51, 1244-1251. [CrossRef]

27. Sutton, M.; Daly, L.; Kirke, P. Survival and disability in a cohort of spina bifida births in Dublin, Ireland. Ir. J. Med. Sci. 2010, 179, 416.

28. UNCRPD. Committee on the Rights of Persons with Disabilities 2006. Available online: https://www.ohchr.org/EN/HRBodies/ CRPD/Pages/ConventionRightsPersonsWithDisabilities.aspx (accessed on 22 November 2021).

29. WHO. Guidelines on the Provision of Manual Wheelchairs in Less Resourced Settings 2008. Available online: https://www who.int/publications/i/item/guidelines-on-the-provision-of-manual-wheelchairs-in-less-resourced-settings (accessed on 22 November 2021).

30. Bongade, S.; Jaywant, S.; Yeradkar, R. Effects of specially designed early self-mobility chair on functional independence in a child with myelomeningocele. Indian J. Occup. Ther. 2018, 50, 139-144.

31. McConachie, H.; Colver, A.F.; Forsyth, R.J.; Jarvis, S.N. Participation of disabled children: How should it be characterised and measured? Disabil. Rehabil. 2006, 28, 1157-1164. [CrossRef] [PubMed]

32. Gerling, K.; Hicks, K.; Szymanezyk, O.; Linehan, C. Designing interactive manual wheelchair skills training for children. In Proceedings of the 2019 on Designing Interactive Systems Conference, San Diego, CA, USA, 23-28 June 2019; Association for Computing Machinery: New York, NY, USA, 2019; pp. 725-736.

33. King, G.; Williams, L.; Hahn Goldberg, S. Family-oriented services in pediatric rehabilitation: A scoping review and framework to promote parent and family wellness. Child Care Health Dev. 2017, 43, 334-347. [CrossRef] [PubMed]

34. King, G.; Law, M.; King, S.; Rosenbaum, P.; Kertoy, M.K.; Young, N.L. A conceptual model of the factors affecting the recreation and leisure participation of children with disabilities. Phys. Occup. Ther. Pediatr. 2003, 23, 63-90. [CrossRef]

35. Wright, A.; Roberts, R.; Bowman, G.; Crettenden, A. Barriers and facilitators to physical activity participation for children with physical disability: Comparing and contrasting the views of children, young people, and their clinicians. Disabil. Rehabil. 2019, 41, 1499-1507. [CrossRef] [PubMed]

36. Rosenbaum, P.; Gorter, J.W. The 'F-words' in childhood disability: I swear this is how we should think! Child Care Health Dev. 2012, 38, 457-463. [CrossRef]

37. Sawatzky, B.; Rushton, P.W.; Denison, I.; McDonald, R. Wheelchair skills training programme for children: A pilot study. Aust. Occup. Ther. J. 2012, 59, 2-9. [CrossRef]

38. Huegel, M.; Otieno, S.; Kenyon, L.K. Validity of the WST and the WST-Q in children with spina bifida: A pilot project. Disabil. Rehabil. Assist. Technol. 2019, 14, 744-750. [CrossRef]

39. McCann, A.; Hannon-Fletcher, M.; Kerr, D.P. Wheelchair Skills Training Programme for Children: A Pilot Study, Ulster University, Institute of Nursing and Health Research; Posture and Mobility Group: Exeter, UK, 2017.

40. Mortenson, W.B.; Oliffe, J.L. Mixed methods research in occupational therapy: A survey and critique. OTJR: Occup. Particip. Health 2009, 29, 14-23. [CrossRef]

41. Tashakkori AaT, C. Sage Handbook of Mixed Methods in Social E Behavioral Research, 2nd ed.; Sage: Los Angeles, CA, USA, 2010.

42. Macdonald, C. Understanding participatory action research: A qualitative research methodology option. Can. J. Action Res. 2012, 13, 34-50.

43. Palibroda, B.; Krieg, B.; Murdock, L.; Havelock, J. A Practical Guide to Photovoice: Sharing Pictures, Telling Stories and Changing Communities. 2009. Available online: www.pwhce.ca/photovoice/pdf/Photovoice_Manual.pdf (accessed on 18 July 2019 ).

44. Feldner, H.A.; Logan, S.W.; Galloway, J.C. Mobility in pictures: A participatory photovoice narrative study exploring powered mobility provision for children and families. Disabil. Rehabil. Assist. Technol. 2019, 14, 301-311. [CrossRef]

45. Walker, M.L. Participatory action research. Rehabil. Couns. Bull. 1993, 37, 2.

46. McGlanaghy, J.; (University of Limerick, Limerick, Ireland); Gowran, R.J.; (University of Limerick, Limerick, Ireland; University of the Sunshine Coast, Maroochydore, QLD, Australia; Maynooth University, Maynooth, Ireland). Draft Wheelchair Skills Information Pack. Unpublished work, 2019.

47. Kirby, R.L.; Mifflen, N.J.; Thibault, D.L.; Smith, C.; Best, K.L.; Thompson, K.J.; MacLeod, D.A. The manual wheelchair-handling skills of caregivers and the effect of training. Arch. Phys. Med. Rehabil. 2004, 85, 2011-2019. [CrossRef] 
48. WHO. Wheelchair Service Training Package; Reference manual for Participants; WHO: Geneva, Switzerland, 2012. Available online: https:/ / apps.who.int/iris/bitstream/handle/10665/85776/9789241505765_eng_refmanual.pdf;sequence=4 (accessed on 22 November 2021).

49. Liu, H.-Y.T.; Chia, R.-M.; Setiawan, I.M.A.; Crytzer, T.M.; Ding, D. Development of "My Wheelchair Guide" app: A qualitative study. Disabil. Rehabil. Assist. Technol. 2019, 14, 839-848. [CrossRef] [PubMed]

50. Campbell, K.; Amare, N.; Kane, E.; Manning, A. Plain-style preferences of US professionals. IEEE Trans. Prof. Commun. 2017, 60, 401-411. [CrossRef]

51. Mason, J. Mixing methods in a qualitatively driven way. Qual. Res. 2006, 6, 9-25. [CrossRef]

52. Kitzinger, J. Qualitative Research: Introducing focus groups. BMJ 1995, 311, 299. [CrossRef] [PubMed]

53. Carpenter, C.; Suto, M. A Practical Guide, Qualitative Research for Occupational and Physical Therapists, 1st ed.; Blackwell Publishing: Oxford, UK, 2008.

54. Krueger, R.A. Designing and Conducting Focus Group Interviews. 2002. Available online: https://www.eiu.edu/ihec/KruegerFocusGroupInterviews.pdf (accessed on 25 April 2019).

55. Hergenrather, K.C.; Rhodes, S.D.; Cowan, C.A.; Bardhoshi, G.; Pula, S. Photovoice as community-based participatory research: A qualitative review. Am. J. Health Behav. 2009, 33, 686-698. [CrossRef] [PubMed]

56. Krueger, R.A. Developing Questions for Focus Groups; Sage: London, UK, 1998.

57. Kirby, R.L.; Swuste, J.; Dupuis, D.J.; MacLeod, D.A.; Monroe, R. The Wheelchair Skills Test: A pilot study of a new outcome measure. Arch. Phys. Med. Rehabil. 2002, 83, 10-18. [CrossRef]

58. MacPhee, A.H.; Kirby, R.L.; Coolen, A.L.; Smith, C.; MacLeod, D.A.; Dupuis, D.J. Wheelchair skills training program: A randomized clinical trial of wheelchair users undergoing initial rehabilitation. Arch. Phys. Med. Rehabil. 2004, 85, 41-50. [CrossRef]

59. Kirby, L.R.; Best, K.L.; Boyce, J.; Cowan, R.; Giesbrech, E.; Kenyon, L.K.; Koontz, A.; MacKenzie, D.; Mortenson, B.; Parker, K.; et al. Wheelchair Skills Program Manual Version 5.0 2019. Available online: https:/ /wheelchairskillsprogram.ca/wp-content/ uploads/WSP-Manual-version-5.0-approved-version.3.pdf (accessed on 22 November 2021).

60. Kirby, R.L. Wheelchair Skills Assessment and Training; CRC Press: Boca Raton, FL, USA, 2016.

61. Keeler, L.; Kirby, R.L.; Parker, K.; McLean, K.D.; Hayden, J.A. Effectiveness of the Wheelchair Skills Training Program: A systematic review and meta-analysis. Disabil. Rehabil. Assist. Technol. 2019, 14, 391-409. [CrossRef] [PubMed]

62. WhatsApp. Privacy Policy 2019. Available online: https://www.whatsapp.com/legal/\#privacy-policy (accessed on 20 June 2019).

63. Krueger, R.A. Moderating Focus Groups; Sage: London, UK, 1998.

64. Braun, V.; Clarke, V. To saturate or not to saturate? Questioning data saturation as a useful concept for thematic analysis and sample-size rationales. Qual. Res. Sport Exerc. Health 2021, 13, 201-216. [CrossRef]

65. Carter, N.; Bryant-Lukosius, D.; DiCenso, A.; Blythe, J.; Neville, A.J. The use of triangulation in qualitative research. Oncol. Nurs. Forum. 2014, 41, 545-547. [CrossRef] [PubMed]

66. Etherington, K. Becoming a Eflexive Researcher Using Ourselves in Research; Jessica Kingsley Publishers: London, UK, 2004.

67. Vaismoradi, M.; Jones, J.; Turunen, H.; Snelgrove, S. Theme development in qualitative content analysis and thematic analysis. J. Nurs. Educ. Pract. 2016, 6, 100-110. [CrossRef]

68. Morgan, D.L. Qualitative content analysis: A guide to paths not taken. Qual. Health Res. 1993, 3, 112-121. [CrossRef]

69. Braun, V.C.; Clarke, V. Successful Qualitative Research: A Practical Guide for Beginners, 1st ed.; Sage: Los Angeles, CA, USA, 2013.

70. Braun, V.; Clarke, V. Using thematic analysis in psychology. Qual. Res. Psychol. 2006, 3, 77-101. [CrossRef]

71. Edwards-Jones, A. Qualitative Data Analysis with Nvivo, 2nd ed.; Sage: Los Angeles, CA, USA, 2014.

72. Limerick Uo. Research Ethics, Education and Health Science. 2019. Available online: https://www.ul.ie/ehs/research-ethics (accessed on 20 March 2019).

73. Lutabingwa, J.; Nethonzhe, T. Ethical Issues in Social Research 2017. Available online: https://vdocuments.site/research-ethics59120f4a0277b.html (accessed on 22 March 2019).

74. Punch, K. Developing Effective Research Proposals, 2nd ed.; Sage: London, UK, 2006.

75. Hennink, M.; Hutter, I.; Bailey, A. Qualitative Research Methods; Sage: London, UK, 2011.

76. Baksjøberget, P.E.; Nyquist, A.; Moser, T.; Jahnsen, R. Having fun and staying active! Children withdisabilities and participation in physical activity: A Follow-Up Study. Phys. Occup. Ther. Pediatrics 2017, 37, 347-358. [CrossRef]

77. Giesbrecht, E.M.; Miller, W.C.; Eng, J.J.; Mitchell, I.M.; Woodgate, R.L.; Goldsmith, C.H. Feasibility of the enhancing participation in the community by improving wheelchair Skills (EPIC Wheels) program: Study protocol for a randomized controlled trial. Trials 2013, 14, 350. [CrossRef]

78. Chen, W.-Y.; Jang, Y.; Wang, J.-D.; Huang, W.-N.; Chang, C.-C.; Mao, H.-F.; Wang, Y.-H. Wheelchair-related accidents: Relationship with wheelchair-using behavior in active community wheelchair users. Arch. Phys. Med. Rehabil. 2011, 92, 892-898. [CrossRef]

79. Rice, L.A.; Sung, J.; Peters, J.; Bartlo, W.D.; Sosnoff, J.J. Perceptions of fall circumstances, injuries and recovery techniques among power wheelchair users: A qualitative study. Clin. Rehabil. 2018, 32, 985-993. [CrossRef]

80. European Commission. Green Paper on Mobile Health ("mHealth"); European Commission: Brussels, Belgium, 2014.

81. Silva, B.M.C.; Rodrigues, J.J.P.C.; de la Torre Díez, I.; López-Coronado, M.; Saleem, K. Mobile-health: A review of current state in 2015. J. Biomed. Inform. 2015, 56, 265-272. [CrossRef] [PubMed] 
82. Giesbrecht, E.M.; Miller, W.C.; Jin, B.T.; Mitchell, I.M.; Eng, J.J. Rehab on wheels: A pilot study of tablet-based wheelchair training for older adults. JMIR Rehabil. Assist. Technol. 2015, 2, e3. [CrossRef] [PubMed]

83. Broderick, J.; TDevine ELanghans, A.; Lemerise, J.; Lier, S.; Harris, L. Designing Health Literate Mobile Apps; Institute of Medicine of the National Academies: Washington, DC, USA, 2014.

84. Sol, M.E.; Verschuren, O.; de Groot, L.; de Groot, J.F.; Fit-For-the-Future!-consortium. Development of a wheelchair mobility skills test for children and adolescents: Combining evidence with clinical expertise. BMC Pediatr. 2017, 17, 51. [CrossRef] [PubMed]

85. Willis, C.; Girdler, S.; Thompson, M.; Rosenberg, M.; Reid, S.; Elliot, C. Elements contributing to meaningful participation for children and youth with disabilities: A scoping review. Disabil. Rehabil. 2017, 39, 1771-1784. [CrossRef]

86. Groff, D.; Kleiber, D. Exploring the identity formation of youth involved in an adapted sports program. Ther. Recreat. J. 2001, 35, 318-332.

87. Bovend'Eerdt, T.J.; Botell, R.E.; Wade, D.T. Writing SMART rehabilitation goals and achieving goal attainment scaling: A practical guide. Clin. Rehabil. 2009, 23, 352-361. [CrossRef]

88. Anderson, D.M.; Wozencroft, A.; Bedini, L.A. Adolescent girls' involvement in disability sport: A comparison of social support mechanisms. J. Leis. Res. 2008, 40, 183-207. [CrossRef]

89. Brunton, L.K. Clinicians are the missing link to sustainable community-based physical activity participation for children with disabilities. Phys. Occup. Ther. Pediatrics 2017, 37, 359-361. [CrossRef]

90. Calhoun, C.; Schottler, J.; Vogel, L. Recommendations for Mobility in Children with Spinal Cord Injury. Top. Spinal Cord Inj. Rehabil. 2013, 19, 142-151. [CrossRef]

91. Rousseau-Harrison, K.; Rochette, A.; Routhier, F.; Dessureault, D.; Thibault, F.; Côte, O. Impact of wheelchair acquisition on social participation. Disabil. Rehabil. Assist. Technol. 2009, 4, 344-352. [CrossRef]

92. Daoust, G.; Rushton, P.W.; Racine, M.; Leduc, K.; Assila, N.; Demers, L. Adapting the Wheelchair Skills Program for pediatric rehabilitation: Recommendations from key stakeholders. BMC Pediatr. 2021, 21, 103. [CrossRef] [PubMed] 